\title{
RADIOCARBON DATES FROM A HOLOCENE DEPOSIT IN SOUTHWESTERN AUSTRALIA
}

\author{
J R Dodson \\ Department of Geography, The University of Western Australia, Perth, Western Australia 6907. \\ Email: johnd@geog.uwa.edu.au. \\ Weijian Zhou \\ Institute of Earth Environment, Chinese Academy of Sciences, Xi’an 710054, Shaanxi Province, China
}

\begin{abstract}
A radiocarbon chronology has been developed using shell, bulk peat, and paired charcoal and pollen preparations from a peat and clay sequence in southwestern Australia. The results indicate the sequence is of Holocene age, and the mid-Holocene was a period of rapid sediment deposition. The earliest record is based on Bothriembyron sp. snail shell and there is a strong indication that the deposit had a stratigraphic hiatus between 9600 and $4700 \mathrm{BP}$. Modern shell of the snail has no ancient reservoir effect. The bulk peat ages were a little younger than associated AMS determinations on hand-picked charcoal and residues from pollen preparations. As a group, paired charcoal and pollen based dates were indistinguishable in age. This implies that the sedimentary charcoal shows no significant storage and transport time in the catchment before deposition. This is important when interpreting pollen records and sedimentary charcoal to reconstruct fire and vegetation dynamics and inter-relationships.
\end{abstract}

\section{INTRODUCTION}

A common practice in the reconstruction of a vegetation and fire history from an area is to select a series of samples for radiocarbon analysis to establish a chronology. It is important that the deposition of pollen and charcoal in sediment result from contemporaneous processes, and in particular that charcoal and pollen production find their way into the sediment without significant storage and transport times from elsewhere in the catchment. In fluvial environments, for example, it is known that wood and charcoal may be incorporated into sediment after significant storage time in the flood plain (Blong and Gillespie 1978). If it can be shown that pollen and charcoal are of the same age then vegetation and fire histories can be compared.

In this study, we report and discuss a number of peat, shell, pollen preparations, and charcoal particles that were selected to establish an overall chronology to underpin a vegetation and fire history record from southwestern Australia (Dodson and Lu 2000). The samples were from a series of peats and clays from a freshwater swamp known as Byenup Lagoon (Figure 1), and they are Holocene in age.

${ }^{14} \mathrm{C}$ dating of fossil pollen preparations are thought to be reliable indicators of age since they do not contain a reservoir effect (Regnell 1992) and they have been shown to be reliable in hardwater regions (Regnell 1992), freshwater lake deposits (Long et al. 1992), and loess (Zhou et al. 1997).

The study region today has hot and relatively dry summers and mild, wet winters when the majority of the mean annual precipitation of about $900 \mathrm{~mm}$ is received. The main vegetation types in the area are mixed Eucalyptus marginata-Corymbia calophylla sclerophyll forest, open forest, and woodlands. Some open forests are subject to seasonal inundation and are dominated by Melaleuca raphiophylla with Gahnia trifida prominent in the understory. In the early Holocene, Casuarinadominated woodland occurred, and from the mid to late Holocene, vegetation similar to the present has generally persisted (Dodson and Lu 2000). Currently there is some debate about the climatic significance of vegetation changes in the Holocene of southwestern Australia. Churchill (1968) has used pollen analysis as a basis to argue for changing precipitation patterns, whereas Newsome and Pickett (1993) believe that the vegetation changes at do not necessarily support a climate change hypothesis. In addition, other evidence suggests that in some regions of the southwest, the changes 


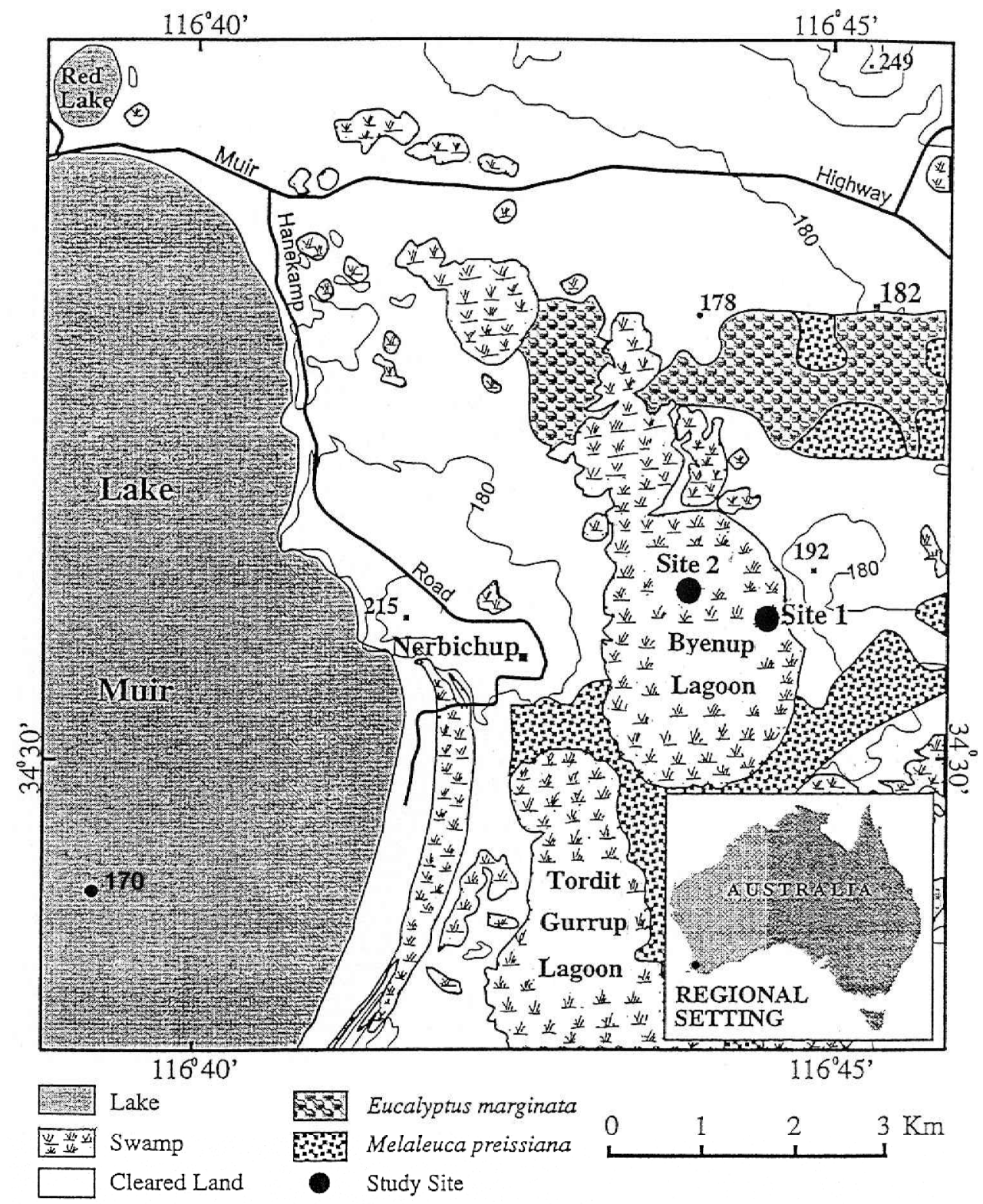

Figure 1 Map of southwestern Australia, showing location of Byenup Lagoon and coring sites for the analyses undertaken in this study 
might be diametrically opposite to those proposed by Churchill (1968) (e.g. Kendrick 1977). Whatever the overall patterns were, it is essential that the evidence is placed in a reliable time-frame for meaningful comparisons across the region.

\section{METHODS}

Sediment samples were collected from Byenup Lagoon with a Russian sampler (Jowsey 1966) in late 1996 (Site 1) and early 1997 (Site 2) after identifying the deepest organic sediment sections in the east and southeast of Byenup Lagoon (Figure 1). Core samples were wrapped in plastic film and aluminium foil in the field and stored at $4{ }^{\circ} \mathrm{C}$ after transport to the laboratory. Dodson and Lu (2000) described the sediment as follows: at Site 1 there was $165.5 \mathrm{~cm}$ of black fibrous peat below which $1 \mathrm{~cm}$ of pale brown peat (10YR 7/3), $2.7 \mathrm{~cm}$ of yellowish brown peat (10YR 5/4), and from 169.2 to $170.0 \mathrm{~cm}$ there was a greenish gray clay $(5 \mathrm{BG} 6 / 1), 0.3 \mathrm{~cm}$ of dark gray clay $(10 \mathrm{YR} 3 / 1)$, and the base of the core (to $170.8 \mathrm{~cm}$ depth) consisted of $0.5 \mathrm{~cm}$ of greenish gray clay. At Site 2 there was a black fibrous peat from the surface to $200 \mathrm{~cm}$, then a transitional shift through $6 \mathrm{~cm}$ of dark gray clay (10YR 3/1), which persisted to the base of the core at $235 \mathrm{~cm}$ depth.

The chronology for the sediment sections was compiled from a series of conventional and accelerator mass spectrometry (AMS) ${ }^{14} \mathrm{C}$ dates on bulk sediment, individual shells of Bothriembyron sp., pollen preparations and hand-picked charcoal fragments retrieved from the sediment (Table 1). The conventional analyses were undertaken in the Radiocarbon Laboratory in the Department of Geography at The University of Western Australia, and staff at ANSTO undertook the AMS analyses. In addition, living snail shells and shell from a clay layer were analyzed by x-ray diffraction at Nanjing University to establish whether calcite was present. Calcite indicates either secondary deposition or recrystallization, since the shell is normally composed of aragonite. Both shell samples were composed of aragonite and their pretreatment at the $\mathrm{Xi}$ ' an Laboratory followed the procedure given in Zhou et al. (1999) for converting them to $\mathrm{CO}_{2}$ then graphite (Slota et al. 1987). The graphite was then dated by AMS.

Samples for the pollen preparations which were dated by AMS were washed and heated to $100{ }^{\circ} \mathrm{C}$ in $10 \% \mathrm{NaOH}$ to remove all traces of humic acids then rinsed to neutrality in $2 \% \mathrm{HCl}$. They were then sieved through a $150 \mu \mathrm{m}$ mesh and washed in a $2.2 \mathrm{gm} \mathrm{cm}^{-3}$ density lithium heteropolytungstate solution, a heavy liquid treatment, then washed in deionized water. The residues at this point contained abundant pollen, but some cellulose as cuticle, fungal hyphae, some fine charcoal, chitin, and some undifferentiated plant matter.

The charcoal samples were hand-picked from remains trapped on the sieved samples used for the pollen preparations. These had already been washed to remove humic acids or traces of carbonate and were also dated by the AMS method.

The shells of Bothriembyron sp. were hand-picked from the sediment. Living animals were collected from the samphire region around the shore of Lake Muir (Figure 1). Shells were boiled in $10 \% \mathrm{NaOH}$ for $20 \mathrm{~min}$ and dried at $105^{\circ} \mathrm{C}$ then submitted for dating by the AMS method.

Two peat samples of about $30 \mathrm{~g}$ were selected for conventional ${ }^{14} \mathrm{C}$ analysis. These were washed in hot $10 \% \mathrm{NaOH}$ and rinsed to neutrality in $10 \% \mathrm{HCl}$ before combustion. 
Table 1 Samples for AMS and conventional radiocarbon dating for Byenup Lagoon

\begin{tabular}{lclllr}
\hline Site & Depth $(\mathrm{cm})$ & Sample & Number & Age $($ yr BP) & $1-\sigma$ error $^{\mathrm{a}}$ \\
\hline 1 & Surface & Shell (living) & XLLQ707 & Bomb affected & NA \\
1 & $0-1$ & Charcoal & OZC521 & Modern & NA \\
1 & $29-30$ & Charcoal & OZC522 & 2270 & 50 \\
1 & $39-40$ & Charcoal & OZC523 & 3280 & 70 \\
1 & $39-40$ & Pollen & OZC524 & 3000 & 60 \\
1 & $49-50$ & Charcoal & OZC525 & 3420 & 150 \\
1 & $49-50$ & Pollen & OZC526 & 3350 & 110 \\
1 & $59-60$ & Charcoal & OZC527 & 3820 & 60 \\
1 & $59-60$ & Pollen & OZC528 & 3500 & 170 \\
1 & $69-70$ & Charcoal & OZC529 & 4170 & 70 \\
1 & $69-70$ & Pollen & OZC530 & 4300 & 60 \\
1 & $79-80$ & Charcoal & OZC531 & 4230 & 100 \\
1 & $99-100$ & Charcoal & OZC532 & 4160 & 80 \\
1 & $119-120$ & Charcoal & OZC533 & 4870 & 80 \\
1 & $139-140$ & Charcoal & OZC534 & 4810 & 160 \\
1 & $155-165$ & Peat & UWA1 & 3925 & 130 \\
1 & $159-160$ & Charcoal & OZC535 & 4700 & 90 \\
1 & $159-160$ & Pollen & OZC536 & 4630 & 70 \\
1 & $169-170$ & Charcoal & OZC537 & 4650 & 90 \\
1 & $200-210$ & Peat & UWA2 & 4285 & 85 \\
2 & $225-230$ & Shell & XLLQ708 & 9695 & NA \\
2 & Surface & Shell (living) & XLLQ707 & Bomb affected & \\
\hline
\end{tabular}

aNA means not applicable.

\section{RESULTS AND DISCUSSION}

The ${ }^{14} \mathrm{C}$ results are shown in Table 1 and these are plotted against depth in Figure 2. The modern shell sample was bomb affected and the oldest age, early Holocene, was from a fossil shell of the same species. Four paired pollen residue and charcoal samples appear to be consistent in age, and when tested with a paired t-test analysis, there is no significant difference in the results $(\mathrm{P}=0.2)$. As a group the AMS ages are consistent, and along with the bulk peat samples, show that the lower organic and clay sections were deposited quickly compared to the rest of the sediment. For Site 1, the AMS ${ }^{14} \mathrm{C}$ determinations are relatively consistent. The major date anomaly comes from a bulk peat sample (UWA 1) that dates a few centuries younger than the AMS samples from charcoal and pollen residues collected around it. One could argue that samples are older than $4100 \mathrm{BP}$ below $60 \mathrm{~cm}$ depth, and between 4600 and $4800 \mathrm{BP}$ for samples between 120 and $170 \mathrm{~cm}$ depth from Site 1 . The Site 2 dates are older than 4000 BP, including the bulk peat sample dated by conventional analysis. The oldest date may indicate relatively discontinuous deposition in the early Holocene at this site, then deposition rates were relatively rapid between about 4000 and $4700 \mathrm{BP}$ then were lower since this time.

The whole sediment sequence has a range of Holocene ${ }^{14} \mathrm{C}$ ages. There are a group of dates which cluster between about 4000 and $4700 \mathrm{BP}$, and since these cover a large range of sediment depths, they indicate relatively rapid deposition during this phase. 


\section{AGE-DEPTH RELATIONSHIP}

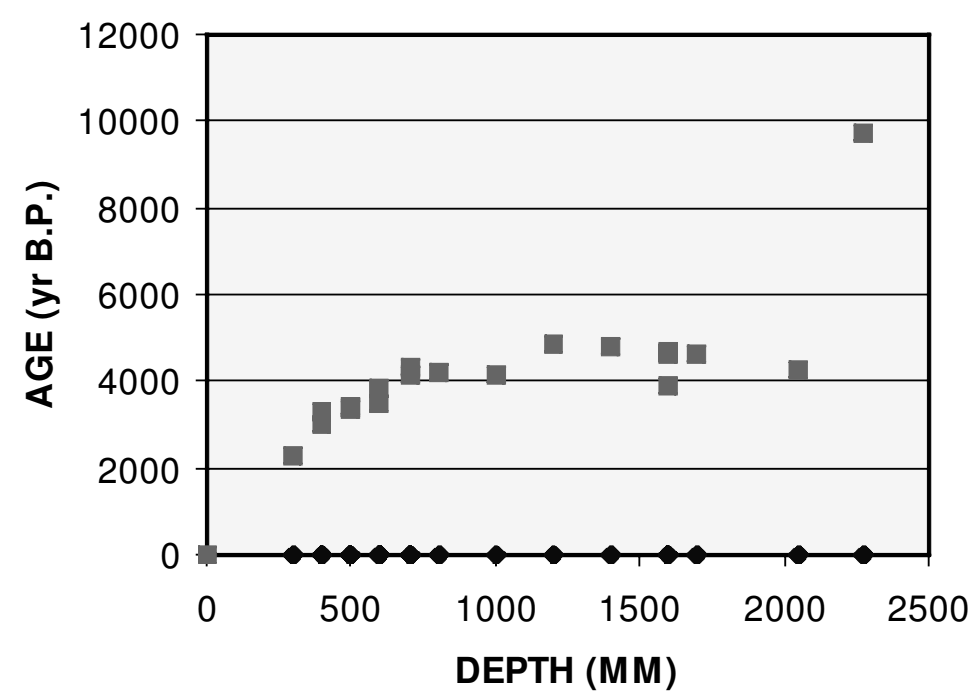

Figure 2 Plot of ${ }^{14} \mathrm{C}$ ages from Byenup Lagoon, southwestern Australia

The shell from a living snail indicated the carbon was bomb affected and suggests there was no ancient reservoir effect. The oldest date returned in the sequence was also a snail shell, and this has no corroborating age determination. The pollen analysis from this site showed that accompanying sediment from depths near this shell sample were dominated by Casuarina woodland rather than Eucalyptus and Melaleuca as is seen in levels of mid-Holocene age and younger. The vegetation change may be climatically significant, perhaps indicating warmer and/or drier conditions in the early Holocene, but whatever it means, it would take some time for a vegetation shift from this to the modern woodlands seen by the mid-Holocene. Indeed, the age difference seen in the dates is therefore not necessarily a dating problem and more likely indicates a stratigraphic hiatus. Thus, on the evidence available, the date of $9695 \mathrm{BP}$ is credible.

The bulk peat samples appear to return younger ages than the surrounding AMS dates. UWA1 returned an age of $3925 \mathrm{BP}$, while bracketing AMS dates on charcoal and pollen residues were in the range of 4600 to $4800 \mathrm{BP}$. The second bulk peat age date (UWA2) of 4285 also appears to be younger than expected; however, with just two bulk peat ages the apparent lower age is best treated as a probable trend rather than a clearly demonstrated difference.

The pollen residue and charcoal samples prepared and analyzed by the AMS method returned a consistent group and trend in ages, and they were not significantly different when measured from the same sediment samples. This consistency has a number of important implications. Firstly, since pollen deposition arrives in the sediment through the atmosphere and with some water transport, with little likelihood of reworking from older material, and should not be influenced by reservoir effects (Regnell 1992), this suggests the same is true for charcoal in this deposit. Thus, if the charcoal has no large lag factor in the time since its production and incorporation into the sediment, it is valid to compare pollen and charcoal changes in reconstruction of vegetation and fire histories. 
The general conclusions from this study then are that bulk peat samples from southwestern Australia may return slightly younger ages than other materials and methods. Dates from the shell of Bothriembyron sp. snails are probably reliable. AMS determinations on pollen and charcoal were found to be consistent and are thus regarded as reliable ${ }^{14} \mathrm{C}$ ages. An important conclusion from this is that fossil charcoal in these peats was deposited contemporaneously with pollen in the same sediment, and this means it is valid to develop vegetation and fire histories from sequences such as these.

\section{ACKNOWLEDGMENTS}

We are grateful for technical assistance by Bill Wilson (Department of Geography), to Dr Ewan Lawson of the Australian Nuclear and Science Technology Organisation (Lucas Heights, Sydney), and to Dr A J T Jull of the University of Arizona for technical support. The Australian Research Council and KZCX1-Y-05 of the Chinese Academy of Sciences funded this research.

\section{REFERENCES}

Blong RJ, Gillespie R. 1978. Old carbon in new sediments. Search 9:166.

Churchill DM. 1968. The distribution and prehistory of Eucalyptus diversicolor $\mathrm{F}$. Muell., E. marginata Donn ex Sm., and E. calophylla $\mathrm{R}$. Br. in relation to rainfall. Australian Journal of Botany 16:125-51.

Dodson JR, Lu JJ. 2000. A late Holocene vegetation and environment record from Byenup lagoon, south-western Australia. Australian Geographer 31:41-54.

Jowsey PC. 1966. An improved peat sampler. New Phytologist 65:245-8.

Kendrick GW. 1977. Middle Holocene marine molluscs from near Guilford, Western Australia, and evidence for climatic change. Journal of the Royal Society of Western Australia 59:53-66

Long A, Davis OK, Lanois JD. 1992. Separation and ${ }^{14} \mathrm{C}$ dating of pure pollen from lake sediments: nanofossil AMS dating. Radiocarbon 34(3):557-60.
Newsome JC, Pickett EJ. 1993. Palynology and palaeoclimatic interpretations of two Holocene sequences from southwestern Australia. Palaegeography, Palaeoclimatology, Palaeoecology 101:245-61.

Regnell J. 1992. Preparing pollen concentrates for AMS dating: methodological study from a hard-water lake in southern Sweden. Boreas 21:373-7.

Slota PJ Jr, Jull AJT, Linick TW, Toolin LJ. 1987. Preparation of small samples for ${ }^{14} \mathrm{C}$ accelerator targets by catalytic reduction of CO. Radiocarbon 29(2):303-6.

Zhou WJ, Donahue D, Jull AJT. 1997. Radiocarbon AMS dating of pollen concentrated from eolian sediments: implications for monsoon climate change since the Late Quaternary. Radiocarbon 39(1):19-26.

Zhou WJ, Head MJ, Wang FB, Donahue D, Jull AJT. 1999. The reliability of AMS radiocarbon dating of shells from China. Radiocarbon 41(1):17-24. 